\title{
THE DIAGNOSIS AND MANAGEMENT OF HYPERTENSION IN PREGNANCY
}

\author{
C. Keith Vartan, F.R.C.S., F.R.C.O.G. \\ British Hospital for Mothers and Babies, Woolwich.
}

WHEN one uses the terms normotension and hypertension one must realise that the distinction between the two is arbitrary and artificial. We know that the blood pressure readings rise slightly with increasing age and scales of acceptable figures have been drawn up. Thus Pickering suggests the following:Age 20-24 Systolic 100-130 Diastolic $60-85 \mathrm{~mm}$. Hg. Age 25-29

Age 30-34 Age 35-39

$\begin{array}{cr}\Rightarrow & 102-130 \\ " & 105-135 \\ " & 105-140\end{array}$

$\begin{array}{ll}” & 60-85 \\ " & 60-88 \\ & 65-90\end{array}$

,

,

A gentle rise in the diastolic pressure over a period of 20 years, yet all within normal range. It is also acknowledged that variations occur in the same individual throughout the day and can be affected by a variety of circumstances. Nevertheless the obstetrician is so well aware of the dramatic variations which take place in pregnancy that he must of necessity draw arbitrary lines between normal and raised pressures and further subdivide the raised into mild and severe elevations in order that he may observe what happens and learn how to deal with them.

There are a great many different possible causes of hypertension in pregnancy.

It may be secondary to phaeochromocytoma, or coarctation of the aorta or it may be a legacy of acute or chronic nephritis, or be a part of Cushing's syndrome and all of these will have to be considered if the hypertension is severe, say 170/100 and upwards when the patient first presents. These disorders are rare however and for the most part all we can say is that a certain number of women have an elevation of their blood pressure above our arbitrary standard of normality, without there being any discoverable cause for it. It may be familial or have been acquired in childhood possibly by undiagnosed pyelonephritis. Most observers acknowledge that about $10 \%$ of women are with these reservations classifiable as being hypertensive, and further that an additional $15 \%$ will develop their hypertension in pregnancy. These two groups are usually designated 'chronic hypertension' and 'preeclampsia'.
Browne (1956) believes that pre-eclampsia unmasks a familial tendency to hypertension. Robert Platt (1958)'s classic case of hypertension in identical twins, one a multipara and one a nullipara supports this. Epstein (1964) however went further than this and showed that pre-eclampsia actually predisposed to hypertension. Gibson and Platt (1959) similarly found higher blood pressure readings 4 years after pre-eclamptic pregnancies, than would have been expected.

A leader writer in the British Medical Journal (1965) concluded his summary of 'Pregnancy Toxaemia and Hypertension' with the question 'Are words and their meanings obscuring the truth?' Again in the same journal (1961) 'A misnomer can hardly ever be eradicated. In this same field the archaic and confusing terminology of the so-called 'toxaemias of pregnancy' has persisted overo the years though it has done little other than provide this aspect of obstetrics with an aura of obscurity'. Pickering has recommended that the term 'toxaemia of pregnancy' be abolished. Lance Townsend (1959) concurs.

In the author's view pre-eclampsia is acute hypertension. In some cases it unmasks a chronic hypertensive tendency, in others it produces it. The terms pre-eclampsia and toxaemia are ripe for eradication.

\section{Diagnosis}

If we are to compare the nurmotensive with the hypertensive we must adopt an arbitrary and personal standard. I personally use the figures of $130 / 70$ which were suggested by F. J. Browne in the 1930's. He is supported in this by Hahn (1952) who reported a mean reading of $117 / 67$ at the age of 15 in an extensive study of schoolboys and by Robinson and Brucer (1939) reporting on blood pressure readings from 11,000 persons and stating that the normal range of the systolic blood pressure was from 90-120 mm. Hg., and of diastolic pressure $60-80 \mathrm{~mm}$. Browne's figure is neither right nor wrong but it is realistic for in two extensive studies of antenatal patients the author 
has found twice that $90 \%$ of women present at the booking clinic with figures below 130/70.

By using this standard then the patients are divided into normotensive $(90 \%)$ and hypertensive $(10 \%)$. Of the former group a further $15 \%$ will develop hypertension, oedema and proteinuria. These are usually called pre-eclamptic, though in my submission those who develop these signs for the first time in pregnancy are acute hypertensives. Similarly a patient with established hypertension who develops oedema and proteinuria is usually said to have developed pre-eclampsia whereas she has really developed an exacerbation of her hypertension. It is important to get nomenclature right. Eden (1906) introduced the term toxaemia to explain how the patient was being intoxicated by the waste products of foetal metabolism added to her own, and the advice given was "to promote the free action of the various organs of excretion". At one period in history the Dublin School was famous for its gastric and colonic lavage as the treatment for severe 'toxaemia'. James Young devoted much time in an attempt to discover toxins in the red infarcts of the placenta which are now acknowledged to be part of an impaired placental circulation, in turn probably caused by an impaired myometrial circulation (Browne and Veale, 1953). The word "pre-eclampsia" was intended to draw the attention of the practitioner to the fact that albuminuria of pregnancy, as it was originally called, was a serious condition and might lead on to eclampsia. Yet it rarely does lead on to eclampsia and many cases of eclampsia are not preceded by albuminuria. The term preeclampsia appears in the 7 th edition of Eden and Holland's Manual of Midwifery (1931). If we could come to regard these artificially separated conditions, pre-eclampsia and chronic hypertension, as acute and chronic hypertension we would bring them closer together and perhaps even give them a common aetiology.

\section{Aetiology}

It was shown by Pollak (1956) that 'preeclampsia' had a specific renal lesion. McCartney (1964) investigated 14 primigravidae clinically diagnosed as having 'pre-eclampsia' by means of renal biopsy, and found 5 to have chronic glomerular nephritis, 2 nephrosclerosis and 2 to have normal renal histology; 5 had the 'toxaemic glomerular lesion' described by Pollak, and they state that the 'toxaemic glomerular lesion differs significantly from all other categories of patients'. 'It is characterised $\frac{2}{3}$ by constricted glomerular capillary lumina, $\stackrel{\mathbb{Q}}{\varrho}$ caused primarily by increase in the cytoplasm $c$ of the glomerular endothelial cells'. Pollak observed that this change, unlike other renal $\stackrel{+}{+}$ pathology, was reversible. On this evidence the kidney is ischaemic in acute hypertension, and $\frac{\bar{F}}{\overline{0}}$ the question to be answered is why? Sophian's (1953) suggestion is that the uterus resists being $\varnothing$ stretched and that the ischaemia is produced \& reflexly. To some exten $\hat{\imath}$ Sophian too has been $\vec{\circ}$ a victim of his own nomenclature in coining the phrase 'Utero-Renal Reflex' for many have $\vec{\omega}$ shown, amongst them Benjamin and Craig $\frac{\text { ? }}{\circ}$ (1961), that it can occur in advanced extra- $\frac{0}{3}$ uterine pregnancy. But why not? The tube is morphologically part of the uterus. The $\stackrel{+}{\mathrm{N}}$ author has also observed all the manifestations $\vec{\infty}$ of acute hypertension, as a post-operative $\stackrel{c}{ }$ complication where much blood had spilled into $\underset{\infty}{\infty}$ the peritoneal cavity. Perhaps "renal-reflex" 응 would have been a better term. Acute hypertension is virtually the prerogative of the $\vec{z}$ primigravida. 37 out of 45 primigravidae with multiple pregnancy in the author's series $\frac{\partial}{5}$ developed acute hypertension, a very high $\overrightarrow{0}$ proportion. Increasing suppression of urine $\frac{1}{18} \mathscr{O}^{\circ}$ a feature of the disorder, as is the diuresis which. follows delivery. The work of Browne and Veal on the myometrial blood flow and of Dixon, Browne and Davey (1963) on the chorio-decidual circulation lends support to tbe $\frac{0}{D}$ concept that the uterus is tense. Furthermore $\varrho$ the blood pressure falls after delivery and it is $\overrightarrow{\overrightarrow{0}}$ acknowledged to fall when the baby is dead, $\exists$ and liquor production presumably ceases and liquor is in fact concentrated. What is not yet acknowledged is that the blood pressure falls and proteinuria diminishes when the baby is dying in utero, but if this is a valid observation, and $I$ believe it to be so, then we have an easy clinical method of telling when the baby's life is in jeopardy, always provided that the patient has not been given hypotensive drugs and diuretics which may produce the same picture, yet without affecting the outcome.

Why some $15 \%$ of apparently normal women $N$ should have a uterus which is unable to fulfil $N$ its function without causing renal ischaemia N is another problem. Duncan, Baird and $\sigma$ Thompson (1952) calls this state of affairs 'physiological failure' and hints at deficiencies $\frac{0}{\Phi}$ in the nutritional and general health of the $\stackrel{\mathbb{\infty}}{\rightarrow}$ patients 'not merely during pregnancy but 0 also during growth and adolescence'.

In this connection the geographical distribu- 
tion of eclampsia in the British Isles is interesting. It is highest in Aberdeen, four times as high as in London. The incidence falls in fact quite steadily from north to south. Perhaps this is accounted for by variation in the standards of living from North to South which could contribute to this variable physiological failure.

There are of course a great many other suggestions concerning the aetiology of 'toxaemia.' In fact it is called the disease of theories. Space does not permit me to go into these seriatim. Sophian (1958) however has reviewed them in Excerpta Medica giving 142 references and anyone anxious to cover this aspect of the disorder is referred to this paper.

\section{Symptoms and Management}

The orthodox symptoms of hypertension in pregnancy are well known but Katharina Dalton (1957) drew attention to the fact that only $7 \%$ of toxaemia patients were free from such minor disturbances as lethargy, headache, irritability and depression. The management consists in organising regular ante-natal visits and also in ensuring that the patient co-operates. At these visits the patient's weight and her blood pressure are recorded and the urine tested. The hypertensive is advised to rest. In some areas free home-help services are available to enable them to do this. A sedative may be prescribed to ensure sleep. A drop in the blood pressure readings during the midpregnancy months is a good prognostic sign however high the initial reading may be. Admission to hospital is necessary if proteinuria occurs; some may be admitted for hyperpyesis and oedema without proteinuria. Patients are admitted for rest and observation and for such treatment as may be called for. The rest is absolute for the first few days during which time the pressure will fall to its basal level. This is presumed to be due to the improved renal circulation. Now the patient is allowed up for part of the day. The effect if any on her pressure will be noted and acted upon.

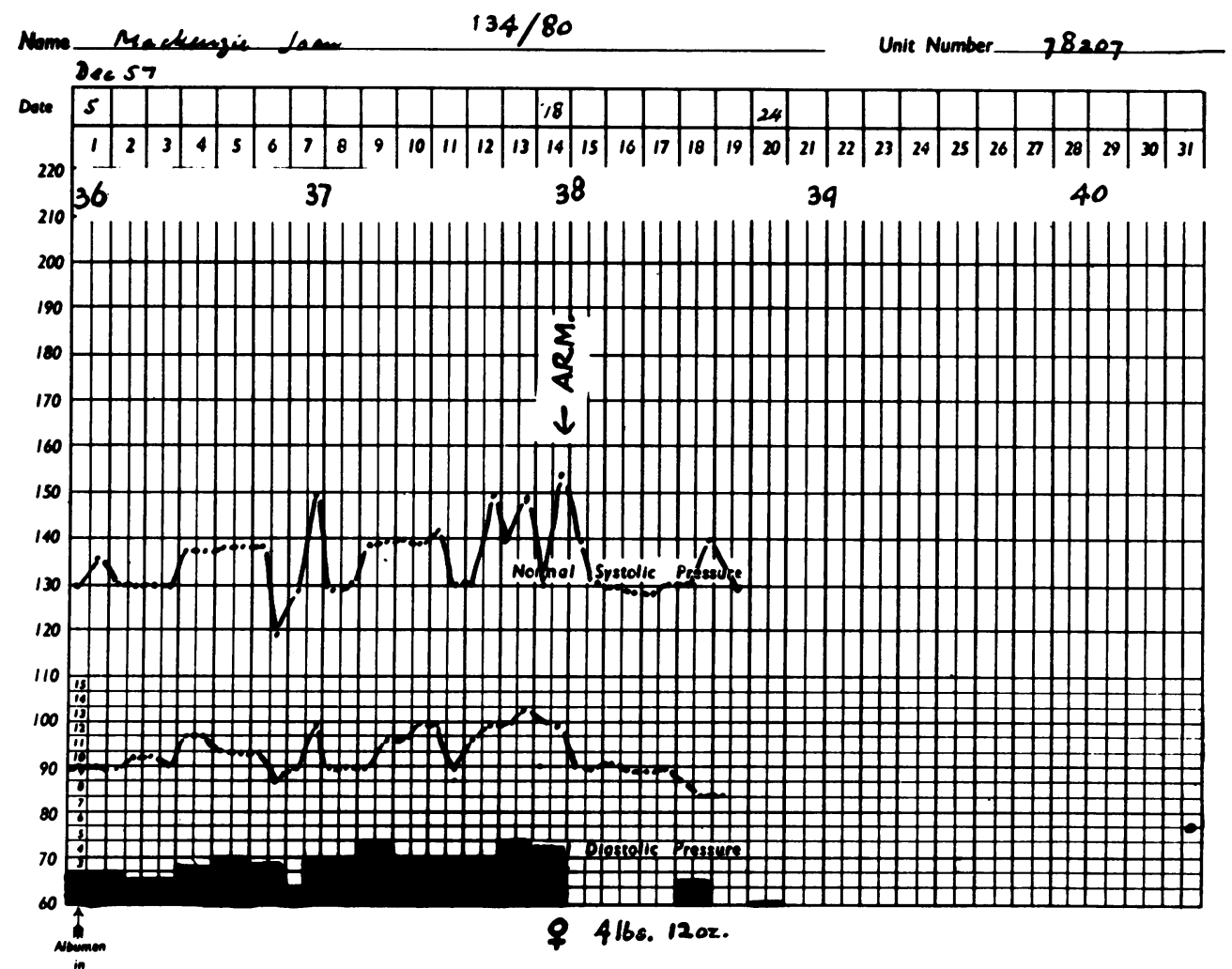

FIG 1.-Chart showing a steady rise in both systolic and diastolic blood pressures and an increase in proteinuria. A chart of good prognosis. 


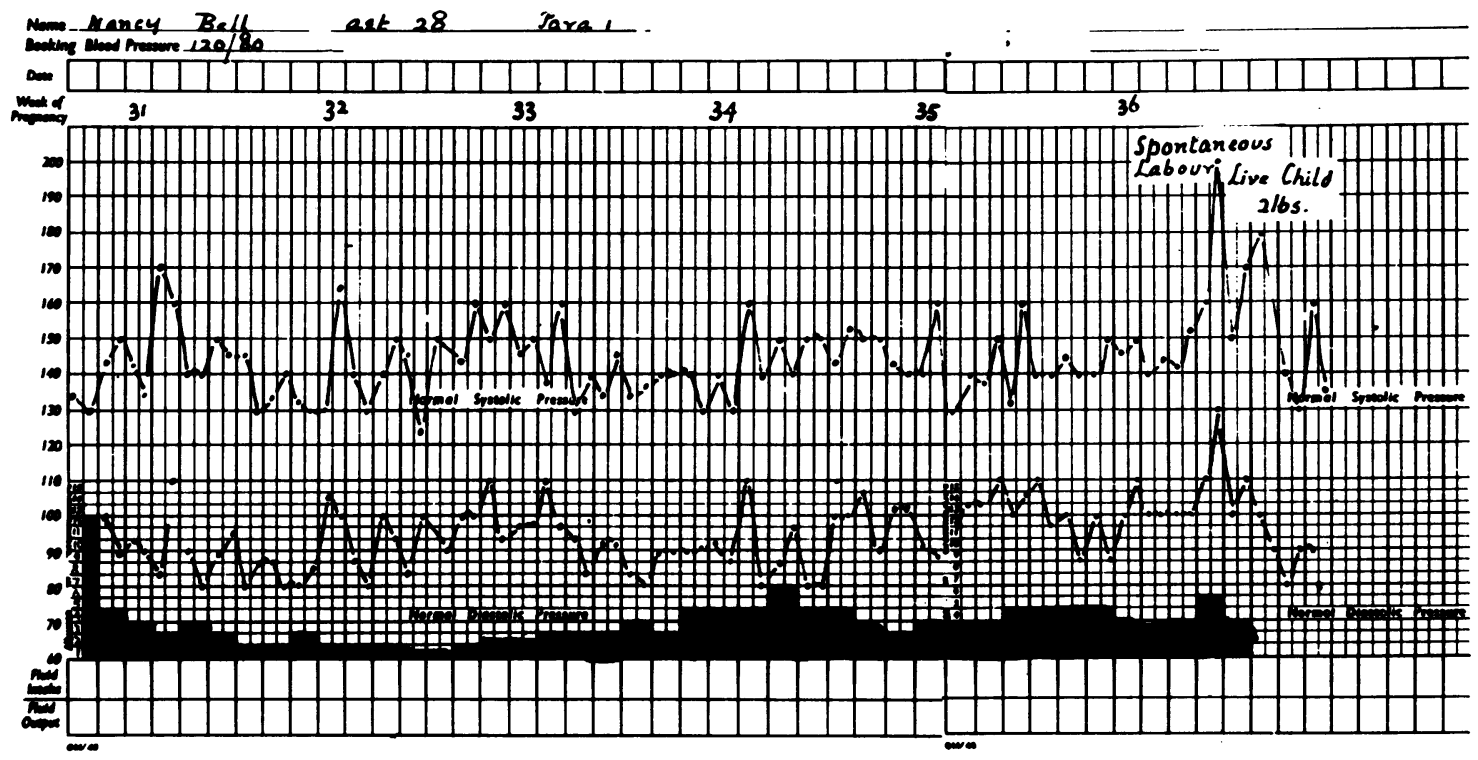

Fig. 2.-Chart showing a stationary level of both systolic and diastolic blood pressures and a more or less even level of proteinuria. A chart of the ultimately, "small for dates" live baby.

The observations are of the systolic and diastolic pressures. These are recorded at the same times every day. The quantity of albumen in the urine is recorded. An Esbach's urinometer reading every 24 hours is accurate enough for this purpose. The urinary output is also recorded daily. The weight is recorded once a week and the foetal heart is auscultated as often as necessary.

Broadly speaking the charts will show one of four trends, after the initial settling has occurred.

1. The pressures may gradually rise together with the quantity of albumen passed. (Fig. 1.)

2. The condition may be static and the record a horizontal one. (Fig. 2.)

3. The pressures may first rise then fall. (Fig. 3.)

4. The records may show a fall from the start.

On Sophian's theory these can be interpreted thus. 1. The baby is growing, and liquor production is normal. The uterus is being increasingly stretched. 2. The baby is not growing though it is alive. Ultimately it will be seen to be 'small for dates'. 3. and 4. mean that the baby is dying, the liquor is not being produced, is in fact being absorbed and the tension in utero is lessening.
This is why with reservations I personall advocate no hypotensive drugs being give or diuretics either. Furthermore Dixon and others have shown that hypotensives do not affect the choriodecidual blood flow. Agar, ڤ Barrett and Exley (1958) noted the failure of $\stackrel{\otimes}{\varrho}$ ganglion-blocking agents to produce improve- $\overrightarrow{\vec{P}}$ ment, and noted fatal ileus in a premature $\frac{0}{3}$ baby probably attributable to the mecamylamine which had been given. In fact all observers state that hypotensive drugs do not improve the prognosis for the child. Watt and Philipp (1960) recording five cases of intra-uterine $\frac{\sigma}{\sigma}$ death while their patients were being given diuretics noted that the blood pressure had $\delta$ fallen and the oedema had lessened and they came to the conclusion that 'two valuable 을 signs of toxaemia of pregnancy are minimised $D$ or lost while the toxaemic process continues.' MacGillivray, Hythen, Taggart and Buchanan N (1962) showed that sodium diuretics had little effect on the progress of the disease. More $O$ recently, however, methyldopa has been shown $\mathrm{W}$ to be beneficial in some series (see Hamilton, p. 195).

Sedatives are allowed if the patient is fretful or sleeping poorly in her new surroundings, but they do not affect the progress of the disorder. 

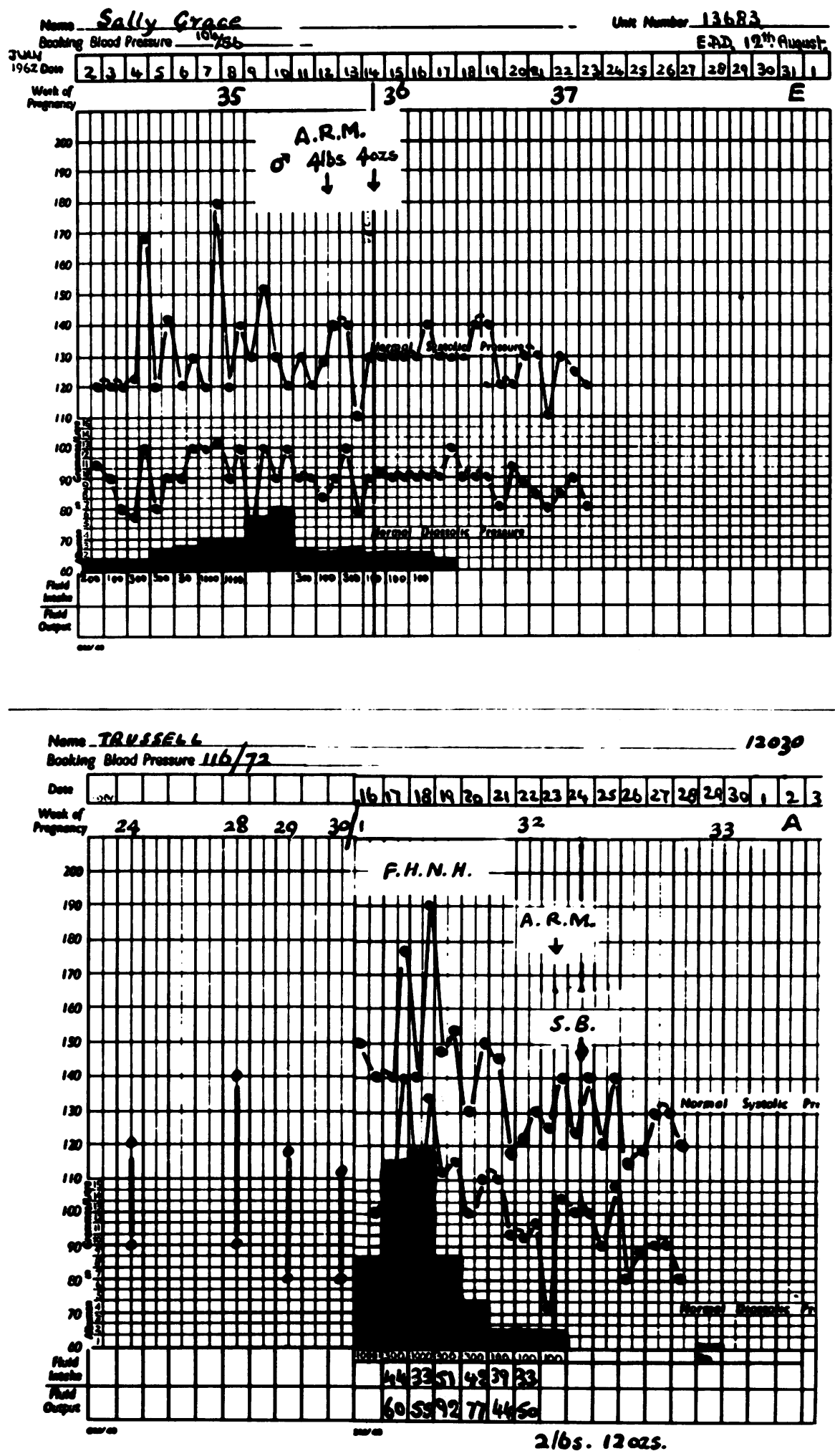

FIG 3.-Charts showing the reversal of the trend of systolic and diastolic pressures in the week preceding the still birth. (In all charts, solid blocks 흠 indicate albumen m.g. 1 litre). 
In-patients are given a diet of $125 \mathrm{~g}$. of protein daily, low carbohydrates and no added salt. Chronic hypertensives may be allowed home after a period of rest but the acute hypertensive is too unpredictable and must be kept under vigilant observation till delivered.

The reservations mentioned above refer to the severer degrees of hypertension, say 180/ 110 to 210/120 which may be encountered, often around the thirtieth week. Here the chance of obtaining a live baby is very remote. If then the patient develops symptoms such as confusion, visual disturbance or headache, she must be given hypotensive drug therapy to prevent a cerebro-vascular accident. For this purpose methyldopa 1-2 g. daily is suitable. Intra-uterine death not infrequently occurs in these cases.

The goal is to get the patient near enough to term to be able to terminate the pregnancy, for this is exacerbating her blood pressure. This is to be balanced against the risk of losing the baby from prematurity. In practice the thirty-eighth week is a reasonable target. Pregnancy may of course have to be terminated very much earlier, often as early as 29 or 30 weeks, in acute hypertension. In this case the baby will almost certainly be lost, but the patient's recovery will be more complete than if the acute process has been allowed to drag on. The risk of the same thing happening a second time is fortunately minimal.

Caesarean section should not be practised unless the baby has a good chance of survival. A stillbirth is easier for the mother to accept than a neo-natal death, and a premature baby has probably as good a chance of survival born naturally, as it does when born by section. Low amniotomy is therefore performed, and if necessary a syntocinon drip infusion can be set up. If this seems to exacerbate the pressure then a hypotensive e.g. mag. sulph. $10 \mathrm{ml}$. of a $20 \%$ solution can be given.

After delivery the blood pressure must be recorded frequently until the patient has had her diuresis. Hypotensives have an important rôle at this stage in preventing post-partum convulsions.

Convulsions (eclampsia) are believed to be caused by spasm of the cerebral arterioles. This has been produced experimentally by feeding salt to rats with hypertension. It is not proposed to deal in detail with the management of these cases. Most are preventable by vigilant ante-natal supervision, and by prompt amniotomy. If they do oocur then heavy sedation is advocated and delivery probably by sec- tion as suon as the condition is under control. If the patient is in labour delivery can be awaited, with emphasis on keeping the patient's airway clear and supplying oxygen to prevent anoxia. After delivery the severe renal ischaemia must be visualised. Diuresis will almost certainly occur spontaneously but if there is anxiety an infusion of $25 \%$ dextrose can be of help.

As to prognosis, most investigations have shown thit there is a quantitative relationship between blood pressure and infant mortality, is and that the risk increases when proteinuria $\vec{\circ}$ appears. When the diastolic pressure is below 100 the foetal wastage is little higher than normal. Landesman (1955) gave these figures: For mild hypertension $(140 / 90$ to $179 / 99)$ $1.7 \%$ but for more severe degrees (180/100 and over) $23 \%$. He further states that with 'super-added pre-eclamptic toxaemia' the figures are $16.4 \%$ and $28 \%$. This emphasises what has been said earlier that the prognosis is worse in acute than in chronic hypertension.

As to the prognosis in the woman, Gladys Dodds states that the outlook for future pregnancies in hypertensive women is favourable below the age of 30 , but becomes less good after the age of 35. This contribution should be read in full. In fact those interested in further reading should study all of the papers in the 'Symposium on non-toxaemic Hyper? tension in Pregnancy' which contains contributions from over 50 authors amongst whom are most of the important contributors to this very interesting subject.

\section{REFERENCES}

Agar, H., Barrett, C. T. H., and Exley, K. A. (1958): Experiences with Mecamylamine in Hypertensive Complications of Pregnancy, J. Obstet. Gynaec. Brit. Emp., 65, 378.

Benjamin, F. and Craig, C. J. T. (1961): Uterine Distension and Pre-Eclamptic Toxaemia, Obstet. Gynaec. Brit. Cwlth., 68, 827.

Browne, F. J. and SHENMACK, D. R. (1956): Chronic. Hypertension following Pre-Eclamptic 을 Toxaemia. The Influence of Familial Hypertension on its Causation, J. Obstet. Gynaec. Brit Emp., 63, 677.

Browne, J. C. McD. and Veale, N. (1953): The Maternal Placental Blood Flow in Normotensive or and Hypertensive Women, J. Obstet. Gynaec. N Brit. Emp., 60, 141.

Dalton, Katharina (1957): Toxaemia of Pregnancy Treated with Progesterone during the Symptomatic Stage, Brit. med. J., ii, 378.

Dixon, H. G., Browne, J. C. MC., Davey, D. A. (1963): Chorio-decidual and Myometrial Blood $\stackrel{\infty}{\longrightarrow}$ Flow, Lancet, ii, 369.

DodDS, GladYS, H. (1950): Symposium on NonToxaemic Hypertension in Pregnancy, p. 200. London: J. \& A. Churchill. 
Duncan, Ethel H. L., Baird, D., Thompson, A. A. (1952): The Cause and Prevention of Stillbirths and First Week Deaths, J. Obstet. Gynaec. Brit. Emp., 59, 183.

EPSTEIN, F. H. (1964): Late Vascular Effects of Toxaemia of Pregnancy, New Engl. J. Med., 271, 391.

Gibson, G. B., and PlatT, R. (1959): Incidence of Hypertension after Pregnancy Toxaemia, Brit. Med, J., ii, 159.

HahN, L. (1952): The Relation of Blood Pressure to Weight, Height and Body Surface Area in Schoolboys aged 11 to 15 years, Arch. Dis. Childh. 27, 43.

LANDESMAN, R. (1955): Foetal Mortality in Essential Hypertension, Obstet. and Gynec., 6, 354.

LeAding ARticle (1965): Brit. med. J., i, 738.

LEAdING ARTICLE (1965): Brit. med. J., ii, 1007.

MoCartney, C. P., Spargo, B., LorinCz, A. B., LEFEBURE, Y. and NEWTON, R. E. (1964): Renal Structure and Function in Pregnant Patients with Acute Hypertension, Amer J. Obstet. Gynec., 90, 579.
MacGillivray, I., Hythen, F. E., Taggart, N. and Buchanan, T. S. (1962): The Effect of a Sodium Diuretic on the Total Exchangeable Sodium and Total Body Water in Pre-eclamptic Toxaemia, Obstet. Gynaec. Brit. Cmwlth., 62, 438.

Platt, R. (1958): Chronic Hypertension following Pre-eclamptic Toxaemia, J. Obstet. Gynaec. Brit. Emp., 65, 385.

Pollak, V. E. (1956): Report on the First Ross Obstetric Research Conference. Univ. Chicago School of Medicine.

Robinson, S. C. and Brucer, M. (1939): Range of Normal Blood Pressure. A Statistical Clinical Study of 11,383 Persons, Arch. intern. Med., 64, 409.

SOPHIAN, J. (1953): Toxaemia of Pregnancy. London: Butterworth.

SopHIAN J. (1958): The Aetiology of Toxaemia, Excerpta med. (Amst.) Sect. II No. 1.

Townsend, L. (1959): High Blood Pressure in Pregnancy. Melbourne: University Press.

WatT, J. D. and Phillipp, E. E. (1960): Oral Diuretics in Pregnancy Toxaemia, Brit. med. J., 1, 1807. 